\title{
Epitaxial growth of tungsten nanoparticles on alumina and spinel surfaces
}

\author{
T Rodriguez-Suarez ${ }^{1}$, A A Díaz ${ }^{2}$, S Lopez-Esteban ${ }^{1}$, C Pecharromán ${ }^{1}$, A Esteban-Cubillo ${ }^{1}$, \\ L Gremillard ${ }^{3}$, R Torrecillas ${ }^{2}$ and J S Moya ${ }^{1}$
}

${ }^{1}$ Instituto de Ciencia de Materiales de Madrid (ICMM), Consejo Superior de Investigaciones Científicas (CSIC), C/ Sor Juana Inés de la Cruz 3, 28049, Cantoblanco, Madrid, Spain.

2 Instituto Nacional del Carbón (INCAR), Consejo Superior de Investigaciones Científicas (CSIC), C/ Francisco Pintado Fe 26, 33011, Oviedo, Asturias, Spain.

${ }^{3}$ Université de Lyon, INSA-Lyon, MATEIS, UMR CNRS 5510, 20 avenue Albert Einstein, VILLEURBANNE F-69621, France.

E-mail: jsmoya@icmm.csic.es

\begin{abstract}
Isolated tungsten nanoparticles $(\alpha-\mathrm{W}$ and $\beta-\mathrm{W}$ phase) were synthesized and epitaxially grown on alumina and spinel surfaces with an average tungsten size of $\leq 20 \mathrm{~nm}$ for a low tungsten content (of $\leq 1.5$ vol. \%). Using tungsten (VI) ethoxide alcoholic solutions, tungsten trioxide hydrated precursors were attached to a ceramic grains surface as a nanoparticles coating. HRTEM micrographs showed epitaxial interfaces between alumina, spinel and metallic tungsten. This epitaxial growth is assumed to be due to the effect of water vapour on the sublimation of ortho-tungstic acid during the reduction process in a hydrogen atmosphere. Planes involved in the epitaxy were found to be $(2 \overline{2} 0)_{\mathrm{Al}_{2} \mathrm{O}_{3}} \|(121)_{W}$ and $(311)_{\mathrm{MgAl}_{2} \mathrm{O}_{4}} \|(110)_{W}$.

\section{Introduction}

Metal nanoparticles are of great interest due to their potential for newly developed applications in a wide variety of fields. However, nanoparticles lose their specific properties on growing or by mutual physical contact when they combine to form aggregates $[1,2]$. This is an important drawback that can be solved by assembling the nanoparticles into well-defined superlattices [3]. Another option is to support or to embed the nanoparticles in microparticles. This can be achieved by exploiting the properties of ceramics and using them as matrices. Indeed, the dispersion of metallic nanoparticles into ceramic matrices is one of the most promising challenges facing materials science today [4].

Tungsten (W) is a metal that possesses exceptional intrinsic properties: an extremely high melting point $\left(3422{ }^{\circ} \mathrm{C}\right)$, high hardness $\left(\mathrm{H}_{\mathrm{V}}=3.43 \mathrm{GPa}\right)$, the lowest thermal expansion coefficient of all metals $\left(4.5 \cdot 10^{-6} \mathrm{~K}^{-1}\right)$ and it also has one of the lowest vapour pressures.

Alumina and spinel are well known refractory ceramic oxides (with melting points $>2000{ }^{\circ} \mathrm{C}$ ) that exhibit a high chemical stability, corrosion resistance and hardness ( $\mathrm{Hv}>15 \mathrm{GPa})$. On the other hand, it is well known that metallic materials on the nanometer scale, present a less ductile behaviour than the same materials of micrometer size [5]. Tungsten has a very high $G$ value (shear module) and therefore, taking into account the linear dependence between $G$ and $H_{V}$, the hardness in tungsten nanoparticles can be expected to increase up to $30 \mathrm{GPa}$. If we also take into
\end{abstract}


consideration the high $\mathrm{H}_{\mathrm{V}}$ values of alumina and spinel matrices, this may result in a ceramicmetal nanostructured powder with a hardness value higher than the one corresponding to microparticulate composite materials [6,7]. Thus these kinds of ceramic-metal nanostructured powder systems are suitable for applications in the abrasive field.

Different preparation routes for ceramic-metal nanocomposite powders can be found in the literature [8-11]. Thin-film deposition methods produce monodisperse nanoparticles but generally only small amounts of sample. Successful large scale syntheses of monodisperse nanocrystals are possible by the inhibition of additional nucleation during growth [12]. Volumetric procedures allow larger amounts of sample to be obtained, although the nanoparticles appear mostly in an agglomerated form. Therefore, with these methods, the synthesis of nanoparticles is not the main problem. The principal problem is how to manipulate these materials so as to avoid the formation of large aggregates.

The processing route chosen for the present investigation is based on the active sites on ceramic oxide surfaces in alcoholic media. When ceramic oxide particles are dispersed in ethanol, protons or hydroxyls are adsorbed onto its surface [13]. The addition of a metal precursor causes a substitution reaction between the metal precursor and the $\mathrm{OH}^{-}$groups on the ceramic oxide particle surfaces [14]. As a direct consequence, a ceramic oxide coating formed by the metallic precursor is obtained. The precursors need first to be decomposed (under suitable thermal treatment) into a metal oxide. Finally, the metal oxide is reduced yielding to the metal nanoparticles attached to the powder surface.

The aim of this work is to describe a new processing route for obtaining nanostructured ceramic-tungsten composite powders. These powders can find applications as abrasives and also in diverse fields such as, catalysis [15-17], inks and pigments [18], and as starting powders in the fabrication of structural ceramic-nW nanocomposites [19].

\section{Experimental procedure}

\subsection{Starting Materials}

The following commercially available powders were used: (1) $\mathrm{WCl}_{6}$ (Tungsten (VI) chloride $99.9 \%$, Aldrich, Germany) (2) $\alpha$-alumina powder (99.99\%, Taimei Chemical Co., Ltd., Japan) with an average particle size of $\mathrm{d}_{50}=300 \pm 50 \mathrm{~nm}$ and (3) alumina rich magnesium aluminate spinel (Alcoa Industrial Chemicals, Germany) with an average particle size of $0.7 \pm 0.3 \mu \mathrm{m}$ and a chemical composition of (wt.\%): $\mathrm{Al}_{2} \mathrm{O}_{3}$ (77.1), $\mathrm{MgO}$ (22.77), $\mathrm{SiO}_{2}(0.05), \mathrm{Fe}_{2} \mathrm{O}_{3}$ (0.08), total impurities being $<0.13$.

\subsection{Synthesis of nanopowders}

The alumina and spinel powders were first calcined at $750^{\circ} \mathrm{C}$ for $2 \mathrm{~h}$ in order to remove any organic additive present in the commercial powder and subsequently passed through a $63 \mu \mathrm{m}$ sieve. Ceramic oxide powders were weighed and dispersed in anhydrous $99.97 \%$ ethanol (solids load of $40 \mathrm{wt}$ \%) and a solution of tungsten (VI) chloride $\left(\mathrm{WCl}_{6}\right)$ in ethanol (diluted to 5 wt. \%) was added dropwise. Powder mixtures with different metallic contents $(1-5$ vol. \%) were prepared for each ceramic oxide matrix. The slurries were first heated under magnetic stirring at $70{ }^{\circ} \mathrm{C}$ and subsequently in air at $60{ }^{\circ} \mathrm{C}$ for $24 \mathrm{~h}$ in order to start nucleation and eliminate any traces of alcohol. The dried powders were crushed and thermally treated at $600{ }^{\circ} \mathrm{C}$ for $1 \mathrm{~h}$ in air to eliminate organic compounds and promote tungsten (VI) oxide $\left(\mathrm{WO}_{3}\right)$ crystallization over ceramic oxide particles. X-Ray analysis was performed to control the decomposition of the tungsten precursor into the most stable oxide $\left(\mathrm{WO}_{3}\right)$. The powders were then sieved down to $63 \mu \mathrm{m}$ before being reduced. Powder reduction was carried out at $900{ }^{\circ} \mathrm{C}$ for $2 \mathrm{~h}$ in a pure $\mathrm{H}_{2}$ atmosphere.

\subsection{Characterization}

The phase evolution of the samples was studied by X-ray diffraction (XRD) (Bruker D8 ADVANCE diffractometer) using $\mathrm{Cu} K \alpha$ radiation and a PSD detector. 
The $\mathrm{W}$ particle size distribution in the specimens was measured from transmission electron microscopy (TEM) images (JEOL microscope, model FXII, JEM 2000, operating at $200 \mathrm{kV}$ ) of the powdered samples.

HRTEM images were produced using a JEOL JEM 200CX microscope at a $200 \mathrm{keV}$ accelerating voltage.

\section{Results and discussion}

Microscopical studies on powders with a metallic content of 1 vol. \% were performed in order to try and understand the growth mechanism of metallic nanoparticles on ceramic oxide grains. Crystallographic planes were identified in HRTEM micrographs and epitaxy between the ceramic oxides and tungsten was observed.

During the drying of the ethanolic tungsten hexachloride solution, $\mathrm{WO}_{3}$ hydrated amorphous nanoparticles are deposited onto ceramic grains. When $\mathrm{WCl}_{6}$ is dissolved in ethanol, a solvolysis reaction takes place [20]. When ethanol is present in excess, the replacement of chloride by the ethoxide groups is complete and $\mathrm{W}\left(\mathrm{OC}_{2} \mathrm{H}_{5}\right)_{6}$ is formed, changing from a yellow colour at the beginning of the dissolution process to transparent when tungsten (VI) ethoxide is formed [21]. After few minutes of continuous stirring under a heating temperature of $70^{\circ} \mathrm{C}$, the solution begins to turn blue, and some of the tungsten (VI) ethoxide decomposes to form $\mathrm{WO}_{3} \cdot \mathrm{H}_{2} \mathrm{O}$ which has a blue colour due to its amorphous nature [22]. Some authors have reported that the blue colour is due to the reduction of $\mathrm{W}^{6+}$ to $\mathrm{W}^{5+}$ by the ethanol, but this phenomenon has only been observed under vacuum [23], nitrogen [21] or argon [24] atmospheres.

After the slurries have dried, the cake formed is made up of alumina or spinel coated by $\mathrm{WO}_{3} \cdot \mathrm{H}_{2} \mathrm{O}$. After the thermal treatments in two consecutive atmospheres, $600^{\circ} \mathrm{C}$ in air and $900^{\circ}$ in $\mathrm{H}_{2}$, the cake yields tungsten nanoparticles perfectly attached to the ceramic grains. Figure 1 shows the XRD patterns for the alumina- 2.5 vol. \% W powder composite after different treatments.

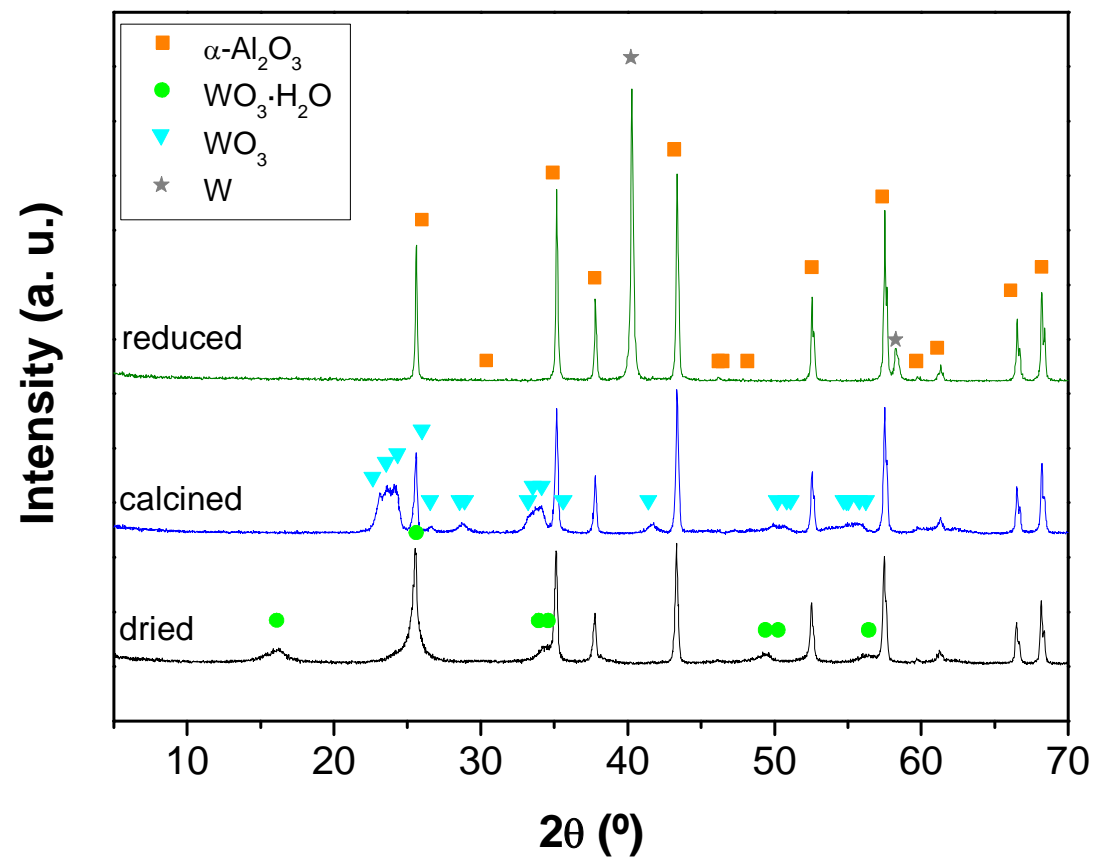

Figure 1. XRD patterns for the different thermal steps followed during the alumina-2.5 vol.\% W nanopowder synthesis.

Figure 2 shows the Differential Thermal Analysis and Thermogravimetry (DTA/TG) of the powder composition performed to justify the temperature of calcination chosen. Up to approximately $300{ }^{\circ} \mathrm{C}, \mathrm{WO}_{3} \cdot \mathrm{H}_{2} \mathrm{O}$ dehydration takes place. However the exothermic peaks that can be observed at 243 and $320^{\circ} \mathrm{C}$, are related to crystalline phase transitions, and more 
specifically, to the cubic and orthorrombic systems, respectively [22]. A calcination temperature of $600{ }^{\circ} \mathrm{C}$ for 1 hour was sufficient to crystallize $\mathrm{WO}_{3}$ over the ceramic grains for all the compositions. For the spinel composites, identical processing steps were followed (data not shown).

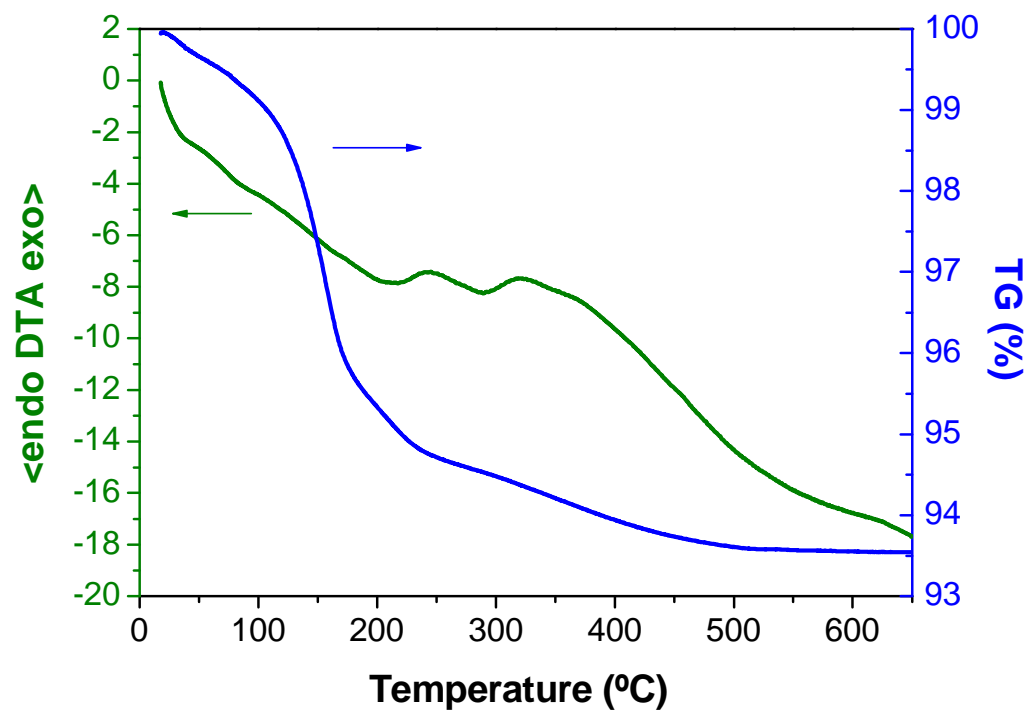

Figure 2. DTA/TG analysis of powder obtained after the drying process prepared for a final composition of alumina- $2.5 \mathrm{vol} . \% \mathrm{~W}$.

The sequence of phases detected by XRD after the different thermal treatments (figure 1) is in perfect agreement with the previous statement. It has been reported before [25-27], that tungsten grows during the reduction process in a hydrogen atmosphere. This is a vapour phase growth due to the formation of $\mathrm{WO}_{2}(\mathrm{OH})_{2}(\mathrm{~g})$ (ortho-tungstic acid). It can be assumed that the water vapour produced by the reduction is responsible for the increase in particle size, because the formation of the volatile compound allows the tungsten to be transported through the gas phase. The formation of the volatile tungsten product is described in the following reactions.

$$
\mathrm{WO}_{3}+3 \mathrm{H}_{2} \rightarrow \mathrm{W}+3 \mathrm{H}_{2} \mathrm{O}
$$

Below about $535{ }^{\circ} \mathrm{C}$, this reaction is incomplete. The water formed is able to react with any unreacted tungsten trioxide present to yield ortho-tungstic acid. Its volatility promotes the growth of the tungsten particle and ultimately determines the size of the nanoparticle.

$$
\mathrm{WO}_{3}+\mathrm{H}_{2} \mathrm{O} \rightarrow \mathrm{WO}_{2}(\mathrm{OH})_{2}(\mathrm{~g})
$$

Ortho-tungstic acid (by inducing the tungsten vapour phase growth) is thought to be the responsible for the epitaxial growth of tungsten nanoparticles over the ceramic oxide grains during the powder reduction process, as well as for the perfect $\mathrm{W}$ crystal faceting observed by TEM (figure 3(a) and (b)).

It was also observed that in the low $\mathrm{W}$ content samples $(\leq 1.5 \mathrm{vol} . \%)$, fractions of very small $\mathrm{W}$ particle sizes $(<7 \mathrm{~nm}$ ) were obtained (as can be seen in figure 3 ).

From the TEM micrographs observation corresponding to mixed powders with a metallic content of 1 vol. $\%$, mean W particle sizes were estimated as $20 \pm 14 \mathrm{~nm}$ for alumina and $18 \pm 9$ $\mathrm{nm}$ in the spinel case. 


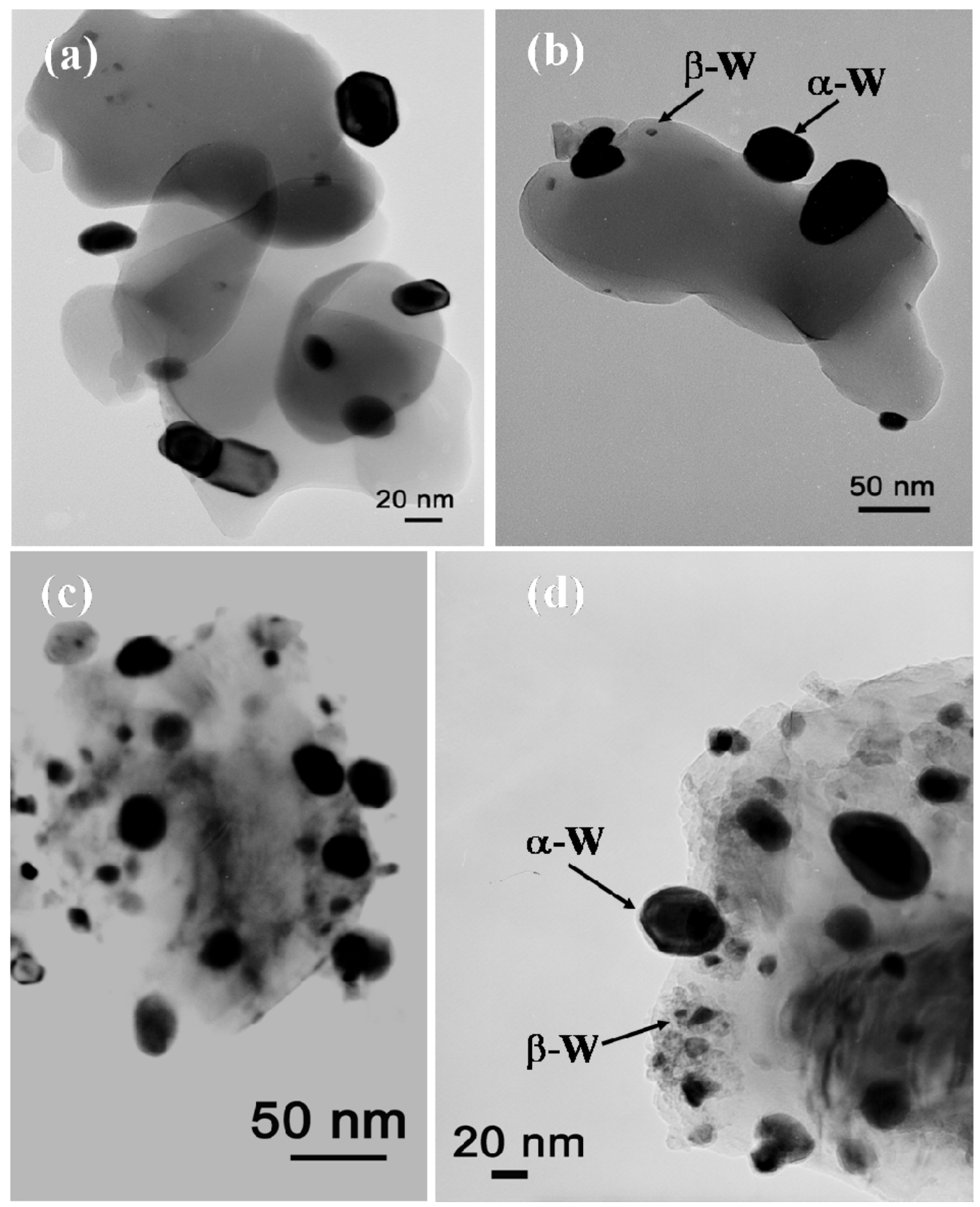

Figure 3. TEM micrographs corresponding to (a), (b) alumina-1 vol. \% $\mathrm{W}$ composites and (c), (d) spinel-1 vol. \% W nanopowder composites.

The pseudohexagonal crystalline habit of the tungsten nanoparticles perfectly attached to the ceramic oxide surfaces, is a clear consequence of tungsten vapour phase growth induced by ortho-tungstic acid [25-27].

After a detailed XRD analysis of the different tungsten content samples (figure 4), the presence of a metastable $\beta-\mathrm{W}$ phase was observed in samples containing $\leq 1.5 \mathrm{vol}$. $\% \mathrm{~W}$. In samples with higher metallic contents, only the stable $\alpha-\mathrm{W}$ phase was detected. The $\beta$-phase is a metastable form and it only appears in sizes $<10 \mathrm{~nm}$ [28].

Figure 4 (a) shows XRD spectra for alumina-W composites with different metallic contents. In order to quantify the fraction of $\beta$-W in the figure 4 (b) we have plotted the diffraction intensity ratio $(\mathrm{R})$ of peak $(210)_{\beta-\mathrm{W}}$ above the peak $(110)_{\alpha-\mathrm{W}}$ versus the vol. $\%$ of $\mathrm{W}$, which is: 


$$
R=\frac{I_{(210)}^{\beta-W}}{I_{(110)}^{\alpha-W}}
$$

The curve plotted in figure 4 (b) is only a guideline for eye.

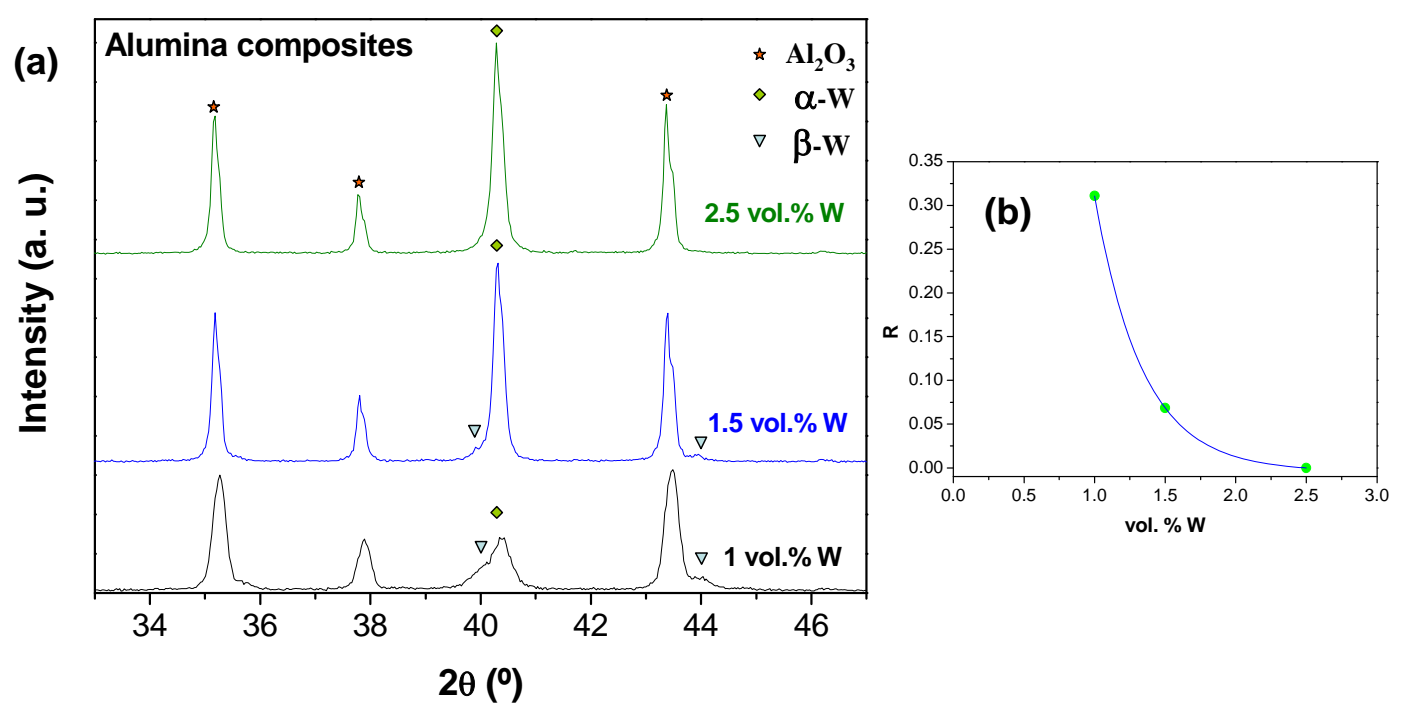

Figure 4. (a) XRD patterns corresponding to alumina-W composite powders with different metallic contents and (b) variation of the maximum diffraction intensities ratio (R) of $\beta-\mathrm{W}$ ((210) peak) over $\alpha-\mathrm{W}((110)$ peak) with the metal content.

As can be deduced from this plot, the fraction of $\beta-\mathrm{W}$ decreases drastically as the $\mathrm{W}$ content increases. In other words, the higher the metal fraction and limited density of active sites, all initial nuclei would grow increasing the final metal particle size. For larger tungsten sizes, as mentioned before, $\alpha-\mathrm{W}$ is the stable phase.

The relative orientation of the alumina and tungsten grains at the interface were identified by HRTEM. The clearest planes are indicated $\left(\mathrm{Al}_{2} \mathrm{O}_{3(012)}\right.$ and $\left.\mathrm{W}_{(110)}\right)$ in figure 5 (a). Fourier analysis was used to find out the type of epitaxy involved. In light of the orientation of each grain and the relative angle of the interface plane, the epitaxial planes appear to be $(2 \overline{2} 0)_{\mathrm{Al}_{2} \mathrm{O}_{3}} \|(121)_{W}$, parallel to the interface. In this composite, tungsten is under compressive stresses ( $\mathrm{d}(121) \alpha-\mathrm{W}=1.29 \AA$ and $\mathrm{d}(2 \overline{2} 0) \mathrm{Al}_{2} \mathrm{O}_{3}=1.19 \AA, \mathrm{d}$ being the spacing between planes). However the stresses caused by this mismatch are not as tense at the interface due to defects and dislocations, as can be seen in figure 5(a).

A close-up view of a single tungsten nanoparticle growing on the spinel surface is shown in figure 5 (b). All the interfaces are sharp and epitaxial growth can be clearly observed. In this particular case, direct image observation leads to the conclusion that the planes involved in the epitaxy were $(311)_{\mathrm{MgAl}_{2} \mathrm{O}_{4}} \|(110)_{\mathrm{W}}$. Here tungsten is under tensile stresses $(\mathrm{d}(110) \alpha-\mathrm{W}=2.24 \AA$ and $\mathrm{d}(311) \mathrm{MgAl}_{2} \mathrm{O}_{4}=2.44 \AA$ ).

In both cases, the lattice mismatch involved is approximately $<8 \%$. This mismatch is not as tense in bulk materials due to dislocations, as in the case of the large $\alpha-\mathrm{W}$ particles. 

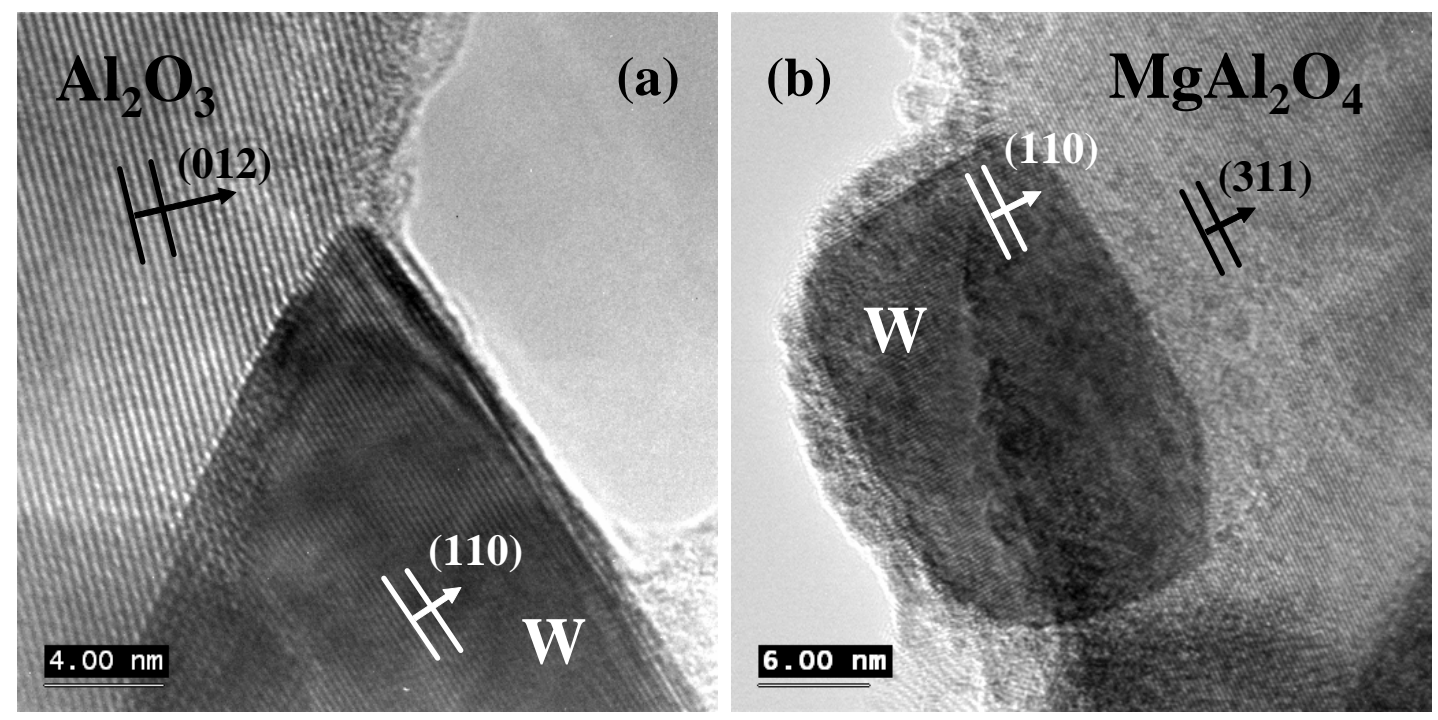

Figure 5. HRTEM micrographs corresponding to (a) alumina-1 vol. \% $\mathrm{W}$ and (b) spinel-1 vol. \% W nanopowder composites.

\section{Conclusions}

Epitaxial growth of tungsten nanoparticles, synthesized from tungsten (VI) ethoxide ethanolic solutions, was observed on ceramic oxide surfaces (alumina and magnesium aluminate spinel). The planes involved in the epitaxy were found to be $(2 \overline{2} 0)_{\mathrm{Al}_{2} \mathrm{O}_{3}} \|(121)_{\mathrm{W}}$ and $(311)_{\mathrm{MgAl}_{2} \mathrm{O}_{4}} \|(110)_{\mathrm{W}}$. Two different tungsten phases, corresponding to alpha and beta, were detected by XRD in composites with a metal content $\leq 1.5$ vol. $\%$.

\section{Acknowledgements}

This research has been supported by the European Union under the IP-NANOKER project (FP6-515784-2), by the Spanish Ministry of Education and Science under the project MAT2006-10249-C02-01 and by the Autonomous Region of Madrid (CAM) under project 200660M011- NanoCeraMetal. S. Lopez-Esteban has been supported by the Spanish Ministry of Education and Science under Ramón y Cajal Program.

\section{References}

[1] Pecharromán C, Esteban-Cubillo A, Torrecillas R and Moya JS 2007 Int. J. Nanotechnol. 4 282

[2] Tian C, Mao B, Wang E, Kang Z, Song Y, Wang C, Li S and Xu L 2007 Nanotechnology 18 285607

[3] Pyrpassopoulos S, Niarchos D, Nounesis G, Boukos N, Zapiropoulou I and Tzitzios V 2007 Nanotechnology 18485604

[4] Moya J S, Lopez-Esteban S and Pecharromán C 2007 Prog. Mat. Sci. 521017

[5] Siegel R W 1993 Nanostruct. Mater. 31

[6] Pecharromán C, Esteban-Betegón F, Bartolomé J F, Richter G and Moya J S 2004 Nano lett. 4747

[7] Moya J S, Rodriguez-Suarez T, Lopez-Esteban S, Pecharromán C, Diaz L A, Torrecillas R and Nygren M 2007 Adv. Eng. Mat. 9898

[8] Hiroki K, Sekino T, Takafumi K, Tadachika N and Niihara K 1993 Ceram.Transact 12867

[9] Laurent CH, Peigney A, Quenard O and Rousset A 1998 Sil. Ind. 63 [5-6] 77

[10] Schuh C A, Nieh T G and Yamasaki T 2002 Scripta Mater. 46735 
[11] Breval E, Dodds G and Pantano C G 1985 Mater. Res. Bull. 20 [10] 1191

[12] Park J, An K, Hwang Y, Park J G, Noh H J, Kim J Y, Park J H, Hwang N M and Hyeon T 2004 Nature Mater. 3891

[13] Wang G, Sarkar P and Nicholson P 1997 J. Am. Ceram. Soc.80 965

[14] Schehl M, Díaz L A and Torrecillas R 2002 Acta Mater. 501125

[15]Yan Y, Xin Q, Jiang S and Guo X 1991 J. Catal. 131234

[16] Sica A M, Santos J H Z, Baibich I M and Gicola C E 1999 J. Mol. Catal.137 287

[17] Cruz J, Avalos-Borja M, Lopez Cordero R, Banares M A, Fierro J L, Palacios J M and Lopez Agudo A 2002 App. Catal. A 22497

[18] Shedd K B 1999 US Department of the Interior. US Geological Survey.

[http://minerals.usgs.gov/minerals/pubs/commodity/tungsten/688499.pdf]

[19] Sekino T and Niihara K 1997 J. Mat. Sci. 323943

[20] Badilescu S and Ashrit P V 2003 Sol. St. Ionics 158187

[21] Sakka S 2005 Handbook of Sol-Gel Science and Technology: Processing, Characterization and Applications I Springer 66

[22] Yamaguchi O, Tomihisa D, Kawabata H and Shimizu K 1987 J. Am. Ceram. Soc. 70 [5] C94

[23] Khodzhemirov V A, Yevdokimova V A and Cherednichenko V M 1976 Polymer Science U.S.S.R. 18 (3) 581

[24] Nishide T, Sawada Y, Habu T and Senda T 1996 Termochimica Acta 27891

[25] Venables D S and Brown M E 1996 Termochim. Acta 285361

[26] Dunmead S D and Moore W G United States Patent 5372797

[27] Smolik G R, Pawelko R J, Anderl R A and Petti D A 2001 Fusion Engineering and Design 54583

[28] Petroff P, Sheng T T, Sinha A K, Rozgonyi G A and Alexander F B 1973 J. Appl. Phys. 44 2545 